\title{
MODEL OF CONSUMER BEHAVIOUR - FEMININE HYGIENE
}

Tanja Rihtaršǐ̌

Gea College Faculty of Entrepreneurship, Ljubljana, Slovenia

Matjaž Rihtaršič

Gea College - Centre of Higher Vocational Schools, Ljubljana, Slovenia
SUMMARY:

This article starts with a review of different recent theoretical views and positions on culture, menstruation taboos, and ethical consumer behaviour. We performed a quantitative research in England, Germany, Slovenia and Sweden on 1,081 responding female students about the effect of cultural and sociological factors on female consumer behaviour when buying feminine hygiene products. Countries were selected depending on different cultures, religions and consumer behaviour. Based on the acquired results, we established a structural model of female consumer behaviour in the selected countries. This model showed a spiral transfer of cultural limitations and prejudices to the respondent students through the environment.

Keywords: model of consumer behaviour, ethical consumerism, culture, taboo, feminine hygiene.

JEL: M31, C38

\section{INTRODUCTION}

\section{Taboo}

Taboos, ceremonies, rituals and sacrifices are often blood-related. Blood is connected with several different meanings. It symbolizes life as well as death. It is no secret that menstruation has been a taboo on a global level for centuries, regardless of the observed differences between cultures. In anthropological language, the word taboo often relates to cultural prohibitions imposed for symbolic, rather than pragmatic, reasons" (Winthrop 1991).

It is a fact that, throughout history, menstrual blood was regarded as disgraceful and the source of evil and toxicity. Menstruation is a taboo since the time of totemistic cultures when the contact with menstrual blood was regarded as dangerous. Members of the tribe believed that their totem is flowing with the blood and that it will destroy any person coming into contact with it (Durkheim 1992). On the other hand, menstrual blood was regarded as sacred and powerful (Stein and Kim, 2009). However, it is clearly visible in everyday life, that menstruation remains a taboo also in the Western countries. Kissling (1996) describes modern taboos related to menstruation as »concealment, behavioural taboos and communication taboos «. The concealment taboo dictates to women that menstruation is something disgraceful and should be concealed. Advertisers skilfully take advantage of this taboo for the purpose of convincing women that nobody will smell, notice or suspect that they are menstruating if they use their advertised products. Menstruating women are stigmatized and 
don't discuss their menstruation. Quite on the contrary, they hide their menstruation at home as well as in public. Because of the fear that others will find out they are menstruating, women avoid public events, sporting activities and sexual intercourse during the time of their menstruation (Britton, 1996). Some women avoid all activities with limited access to the bathroom such as: camping, concerts, picnics, etc., all in fear of bleeding and disclosure of their menstruation.

The behavioural taboo is related to everyday life and sporting activities. $33 \%$ of US women believe that bathing, swimming and sporting activities are not allowed during menstruation. The third taboo, communication taboo, restricts communication about menstruation, not only in company of men, but also in company of women or in the family circle. Williams (1983) notes that $33 \%$ of suburban girls believe that it is inappropriate to talk about menstruation with their fathers and that almost all of them believe that girls should not talk about menstruation with boys. Kissling (1996) warns that mothers are more comfortable to talk with their daughters about pregnancy than menstruation. Discussion about menstruation is often unpleasant for parents and they subconsciously postpone it or wait for the »right moment«. This is the reason why even today girls are not prepared for their first menstruation or why they start searching for information about this topic outside their family circle.

Girls find information about first menstruation from various sources such as parents, school, friends, media, advertisements (Havens and Swenson 1989; Britton 1996). Despite the various sources of information about menstruation, girls still report that they received poor information and that they were not prepared for their first menstruation (Koff and Riordan, 1995). Information about menstruation is mainly focused on the role of ovaries, menstruation and reproduction. Such information is often without practical tips on how girls should behave during menstruation, whether they are allowed to swim, dance, wash their hair, which products are available, etc., or how they will feel during menstruation
(Kissling 1996). There is no doubt that sources of information in connection with culture and social environment have direct impact on the development of the attitude of women towards menstruation. Besides family environment, the establishment of positions and attitude towards menstruation is also influenced by the wider social environment, where the religion, the girl was raised in and whose values she adopted, plays a very important role. In Europe, menstruation was regarded as sin and a curse until the middle of the 20th century. Religions of that time considered women as mothers and wives. Female sexuality, menstruation and the role of women in traditional patriarchal societies were taboos with negative connotation. Žvelc notes that » women who are raised Catholic or who adopt Catholic religion also adopt the concepts of this religion which affect their perception and the experience of menstruation. The process of identification with the concepts of the church as the process of their influence on the experience of menstruation takes place mainly on the unconscious level« (Žvelc 2003). A very important role is given to educational contents about menstruation within the framework of sex and health education in schools. Experts warn that education about menstruation is focused on education about the physiology of the menstrual cycle and does not include information about the worries, fears, mood swings, behaviour, etc. (Prendergast 1994; Kissling 1996; Rembeck, Moller and Gunnarsson 2006). Educational material on menstruation is often sponsored by manufacturers of feminine hygiene products and contains a lot of negative messages and therefore a negative attitude towards menstruation: Menstruation is dirty, shameful and should therefore be concealed from others (Houppert 1999; Kalman 2003).

\section{CULTURE}

Culture is not characteristic of individuals but always a collective phenomenon since the individual shares it, at least partially, with people who live or have lived in the same social environment, i.e. where this individual learned this culture. Culture is a collective 
programming of the mind due to which the members of an individual group or category differ from other groups or categories (Hofstede, 2001).

Cultural orientation of a particular society reflects the complex interaction of values, attitudes and behaviours expressed by the members of this society. Individuals express their culture through the values which they acquired in life and from their environment. In accordance with their attitudes, values demand the most appropriate and effective behaviour in a certain situation. The constantly changing behaviour pattern of an individual and the group affects the culture of the society. The rotation process starts back from the beginning (Heinze 1995).

The culture itself affects the life of people in the community. Cultural patterns strongly intertwine with taboos and attitude towards menstruation. Behaviour of women and their attitude towards menstruation are connected with cultural patterns in form of »unwritten « codes of behaviour.

\section{ETHICAL CONSUMERISM}

Brinkmann (2004) considers that there are four types of ethical consumerism: 1) positive shopping, favouring ethical products (FT, organic food products, feminine hygiene products made of organic cotton or animalfriendly products); 2) negative shopping, which means avoiding the products with which we do not agree (eggs from caged hens or cars with high $\mathrm{CO} 2$ emissions, Always sanitary pads); 3) shopping based on corporate policy as a whole (boycotts of Nestle and buying 'Body Shop' products or 'Natracare' products); 4) the fourth transparent approach is a combination of the previous three and means that the consumer is looking for companies and products together and evaluates which is the most ethical brand. Information about feminine hygiene products and procedures used in their development lead to the development of ethical consumerism in the field of feminine hygiene. Ethical consumerism at first developed in the field of the production and use of tampons. The materials themselves are extremely important.
Viscose fibres were once trees, whilst lifethreatening pesticides are used in the US for the production of cotton. Applicators are made of plastic materials in combination with petroleum products which are simultaneously also extremely harmful to the health of the workers producing such products. Disposal of products represents a major problem, especially disposal of applicator tubes which are a major ecological problem in the US and UK (Davidson, 2012). Seas and shores are overflown with applicators which are regularly being removed by volunteers in clean-up operations.

The field of feminine hygiene includes all forms of ethical consumerism such as positive and negative shopping, i.e. boycott and combined approach. In the US as well as in UK it is possible to notice anti-tampon movements which started in the 1990's after the unfortunate events and the TSS in connection with 'Rely' tampons. Besides TSS, a major problem in the past was dioxin which appeared during bleaching of materials with chlorine. Female US students began to organize themselves in societies with the objective to warn other women about the danger of the use of tampons. Soon, they started to use the internet to promote the use of »harmless « products such as the menstrual sponge, cup or washable sanitary pads (Kissling, 2006).

\section{MODELS OF ETHICAL CONSUMER BEHAVIOUR}

Throughout the review of the literature we can notice various models of ethical consumer behaviour. In most cases the very core of the model contains the logic of a »deliberate action« or »planned behaviour «. So it is all about the knowledge or beliefs that lead to the establishment of positions that effect intention and behaviour (De Pelsmacker in Janssens, 2007). The intention or behaviour can also be affected by the subjective norms and factors controlling the behaviour (Hunt and Vitell 1986; Shaw and Clarke 1999; Vitell, Singhapakdi and Thomas 2001; Shaw 
and Shiu 2002, 2003). Hunto and Vitellov's model (1986) describes the consumer's decision making process with the help of various philosophical aspects that represent the basis for the consumer's moral judgement. On the basis of qualitative research, Shaw and Clark (1999) suggested a conceptual model where the factors affecting beliefs play the key role. The core of the above stated models also includes the sequential logic »beliefs -positions - behaviour«. Transfer of information about moral questions and/ or dilemmas affects the beliefs, positions and behaviour of the consumer. Behaviour is also affected by the detected control of the behaviour or the degree to which the consumers believe that their actions will reach the desired effect, and situational factors such as: price, availability and accessibility which are added as variables determining intention and behaviour. Besides positions towards FT, subjective norms and control behaviours, Shaw and Shiu $(2002,2003)$ also studied the role of the moral commitment and selfesteem. The influence of the subjective norm turned out as statistically irrelevant, whilst the positions and individual characteristics had a tremendous effect on shopping decision making. Amongst the limitations the authors state that the establishment of models in the future should include the influence of information. In their model,
Shaw and Clark (1999) stress the important role of information, literature, advertising and labelling of products when establishing positions and behaviour, and, on the other hand, note the importance of situational factors and product-related factors: price, availability, accessibility, information and time. Other studies on the ethical consumer behaviour identified similar factors which prove that positions often poorly predict ethical consumer behaviour (De Pelsmacker and Janssens, 2007).

Browne et al. (2000) and Roberts (1996) warn about the fact that so-called »ethical products « are too expensive and that, in the eyes of the consumer, the high price does not outweigh the price premium. Other researches show that the price, quality of the product and convenience of purchase are often the most important factors when deciding to purchase something. Carrigan and Attalla (2001) believe that ethical shopping arises when, during shopping, the consumer does not experience higher costs of the price premium, lower quality and poor product accessibility. On the basis of observations of female consumer behaviour, feminine hygiene product manufacturers, market trends and theoretical background, we established a theoretical model which represents the starting point to test the model of female consumer behaviour.

Figure 1: Basic model of female consumer behaviour

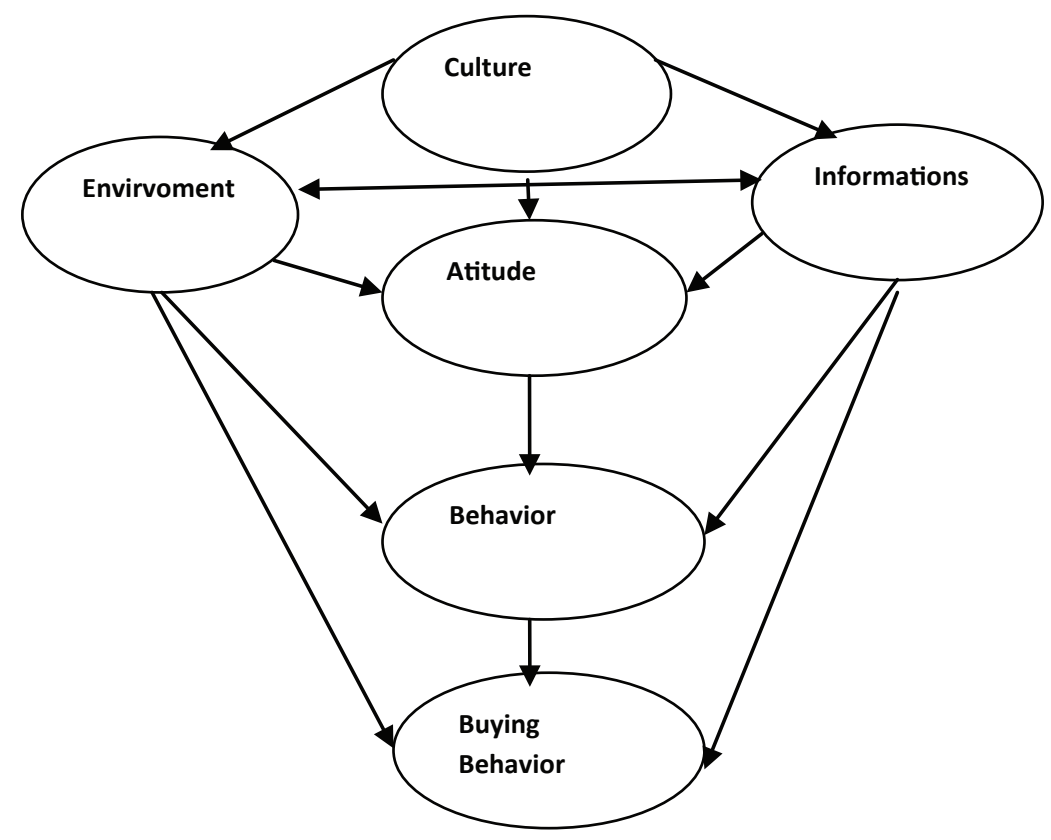


Culture (greatly influenced by religion) affects the environment and information establishing the attitude of society and women towards menstruation. Environment and information also have direct effect on behaviour and consumer behaviour. Attitude of women towards menstruation, which can be positive, negative or mixed, directly affects the behaviour influencing consumer behaviour.

\section{METHODS}

As part of the review of the conceptual model we performed an exploratory factor analysis in order to reduce the large number of the observed of the value of variables $(>1)$, scree diagram and the interpretation of the acquired factors. Reliability of data for individual constructs is checked with Cronbach Alpha. Higher values mean more reliable data. Values of Cronbach Alpha ranged between 0.723 and 0.913 which means that data is very reliable.

As a first step, we had to determine whether the data is adequate for factor analysis. For this purpose we used the Bartlett test and KaiserMeyer-Olkin (KMO).

Table 1: Adequacy of variables of constructs Culture, Information, Environment and Behaviour

\begin{tabular}{|c|c|c|c|c|c|}
\hline \multicolumn{2}{|c|}{ KMO and Bartlett's Test } & KULTURA & INFORMACIJE & OKOLJE & VEDENJE \\
\hline \multicolumn{2}{|c|}{ Kaiser-Meyer-Olkin Measure of Sampling Adequacy. } & 758 & 765 & 711 & 740 \\
\hline \multirow{3}{*}{$\begin{array}{l}\text { Bartlett's Test of } \\
\text { Sphericity }\end{array}$} & Approx. Chi-Square & 2180,917 & 1229,159 & 948,172 & 1142,055 \\
\hline & df & 3 & 6 & 6 & 6 \\
\hline & Sig. & 0,000 & ,000 & ,000 & 000 \\
\hline
\end{tabular}

variables to a smaller number of latent variables (factors). With the help of the exploratory factor analysis we searched for the answer to the question of how many factors are needed to present the data (Hair 2010).

On the basis of the theoretical model we presumed the following factors; culture, environment, information and behaviour. Firstly, we must determine the adequacy of data for further analysis. We performed the factor analysis with the method of maximum likelihood (ML) and the oblique factor rotation together with the Kaiser normalization. The number of factors was determined with the help
Reliability p (sig.) is for all constructs lower than 0.05 which means that the test is statistically significant and that connections between the variables exist also in the population. Values of the KMO test ranged between 0.711 and 0.765 which means that the data is adequate for further analysis. In the second part we determined the communalities of individual variables. We excluded variables with inadequate communalities from further research. We set the criterion to exclude all variables with communality $<0.2$. Claims of individual sets were already determined in the questionnaire itself.

Table 2: Correlations of the selected constructs »Information«, "Behaviour « and »Environment «

\begin{tabular}{|c|c|c|c|c|c|}
\hline \multirow{5}{*}{ INFORMATION } & Factor & 1 & 2 & 3 & 4 \\
\hline & $\begin{array}{lll}1 & \\
\end{array}$ & 1.000 & -.323 & .225 & .477 \\
\hline & 2 & -.323 & 1.000 & -.113 & -.410 \\
\hline & 3 & .225 & -.113 & 1.000 & .140 \\
\hline & 4 & .477 & -.410 & .140 & 1.000 \\
\hline \multirow{3}{*}{ ENVIRONMENT } & 1 & 1.000 & 0.223 & .357 & \\
\hline & 2 & -.223 & 1.000 & .398 & \\
\hline & 3 & .357 & 0.398 & 1.000 & \\
\hline BEHAVIOUR & 1 & 1.000 & -.657 & & \\
\hline
\end{tabular}

Source: Rihtaršič, own research 2014. 
Structuring equation modelling (SEM) is a statistical method where the confirmation approach is used to test and confirm hypothesis of individual events, actions, theories or phenomena. Analysis of several different variables is typical. The set model is tested as a whole, whilst individual variables are tested as a part of the whole (Byrne, 2010). Validity of our model is tested with structural modelling with the help of the AMOS program. Validity is checked with the confirmatory factor analysis (CFA) of actual data and with the aforementioned exploratory factor analysis (EFA). EFA is aimed to identify and reduce the number of variables, whilst CFA is aimed to check whether the observed variables adequately measure (describe) the latent variables and their behaviour also in the structural model. Adequacy of each model is statistically tested. If the model fits with the data, data is adequate. Connections between individual constructs show how well they were assumed depending on the theory. The extent to which the data fits the model can be measured with various adequacy indices such as RMSEA, GFI, CMIN, RMR, CFI, TLI, NFI, PNFI and others.

Table 3: Adequacy model indicators countries and the procedure of structural equation modelling with the help of AMOS. Basic information about the model can be found amongst the results of the model.

Table 4: Basic information about the structural model Minimum is reached

Chi-square $=860.072$

Degrees of freedom $=98$

Reliability $=.000$

Source: Rihtaršič, own research 2014.

\section{DATA COLLECTIONS}

Countries were selected depending on different cultures, religions and consumer behaviour. The research sample included 399 units from Slovenia and 1 unusable unit. Research samples in other countries: Sweden 240 useful and 3 unusable units. Germany - 210 useful units and 5 unusable units; Great Britain - 232 useful units and 13 unusable units. The research

\begin{tabular}{|c|c|c|c|c|c|c|c|c|}
\hline & \multirow[b]{2}{*}{$x$} & \multirow[b]{2}{*}{ df } & \multirow[b]{2}{*}{ p } & \multicolumn{2}{|c|}{ Absolute fit indices } & \multicolumn{2}{|c|}{ Normed fit index } & $\begin{array}{l}\text { Relative fit } \\
\text { indices }\end{array}$ \\
\hline & & & & \multirow{2}{*}{$\begin{array}{l}x^{2} / \mathrm{df} \\
\leq 3,0\end{array}$} & RMSEA & NFI & CFI & PNFI \\
\hline Valid values & & & & & $\leq 0,10$ & $\geq 0,8$ & $\geq 0,9$ & $\geq 0,6$ \\
\hline Model & 837,204 & 95 & 0 & 8,813 & 0,086 & 0,871 & 0,884 & 0,69 \\
\hline
\end{tabular}

Source: Rihtaršič, own research 2014.

The RMSEA indicator amounting to .086 was used as the absolute fit value. This is less than 0.1 and represents a good fit. As the basic incremental fit indicator we used the CFI indicator with a value lower than the maximum permissible value. The parsimony indicator (PNFI) amounted to 0.69 which is higher than the minimum permissible value of 0.6. Based on indicators we can conclude that the data closely fits the model.

With the above procedure we tried to find the structural model of consumer behaviour in selected countries based on theoretical background, acquired data in individual pattern therefore included 1,081 respondents or useful units in total. The majority of units was excluded due to their mismatch with the presumptions of our research because we decided that our research sample only contained the population of female students in a certain selected country. As the limit of usefulness we determined that at least $90 \%$ of all questions in the questionnaire had to be answered. We considered this as the biggest limitation of our empirical study (i.e. the study is performed on a »convenient « research sample). We shall not be able to generalize the acquired data to the whole population. Population of female students was chosen for two reasons: 1) we 
were interested in the trends of behaviour of young women; 2) we estimated that the life style and standard of female students is similar in all countries, regardless of the cultural differences between countries.

Table 5: Proportion of units in the research sample depending on the population for individual countries

\begin{tabular}{|l|l|l|l|}
\hline Country & $\begin{array}{l}\text { Tertiary education } \\
\text { female students }\end{array}$ & $\begin{array}{l}\text { Number of units in } \\
\text { the research sample }\end{array}$ & $\begin{array}{l}\text { \%o units of the } \\
\text { research sample } \\
\text { depending on the } \\
\text { population }\end{array}$ \\
\hline Great Britain & 220,000 & 232 & 1.1 \\
\hline Germany & $1,245,241$ & 210 & 0.2 \\
\hline Slovenia & 52,336 & 399 & 7.6 \\
\hline Sweden & 160,000 & 240 & 1.5 \\
\hline
\end{tabular}

Source: Office for National Statistics; Destatis Statistisches Bundesamt; Statistični urad Republike Slovenije; Ukä Universitet Kenslers Ämbetet, 2015.

The data was collected with the help of a questionnaire. This questionnaire was prepared on the website portal $»$ surveymonkey. com« which is specialized for research. The questionnaire in the language of the selected

Figure 2: Monthly expenditure for feminine hygiene products in EUR in the selected countries country was published on websites of at least 5 different faculties in the selected countries. Collection of data took place from the middle of March 2013 until the end of October 2013.
As the measure of value of consumer behaviour we used the variable in the model marked COM. We asked the responding females how much they spend monthly on feminine hygiene products. The answers were less than EUR 3, more than EUR 3 and less than EUR 5, more than EUR 5 and less than EUR 10, more than EUR 10 and less than EUR 15, and more than EUR 15. Answers were properly valued within the model.

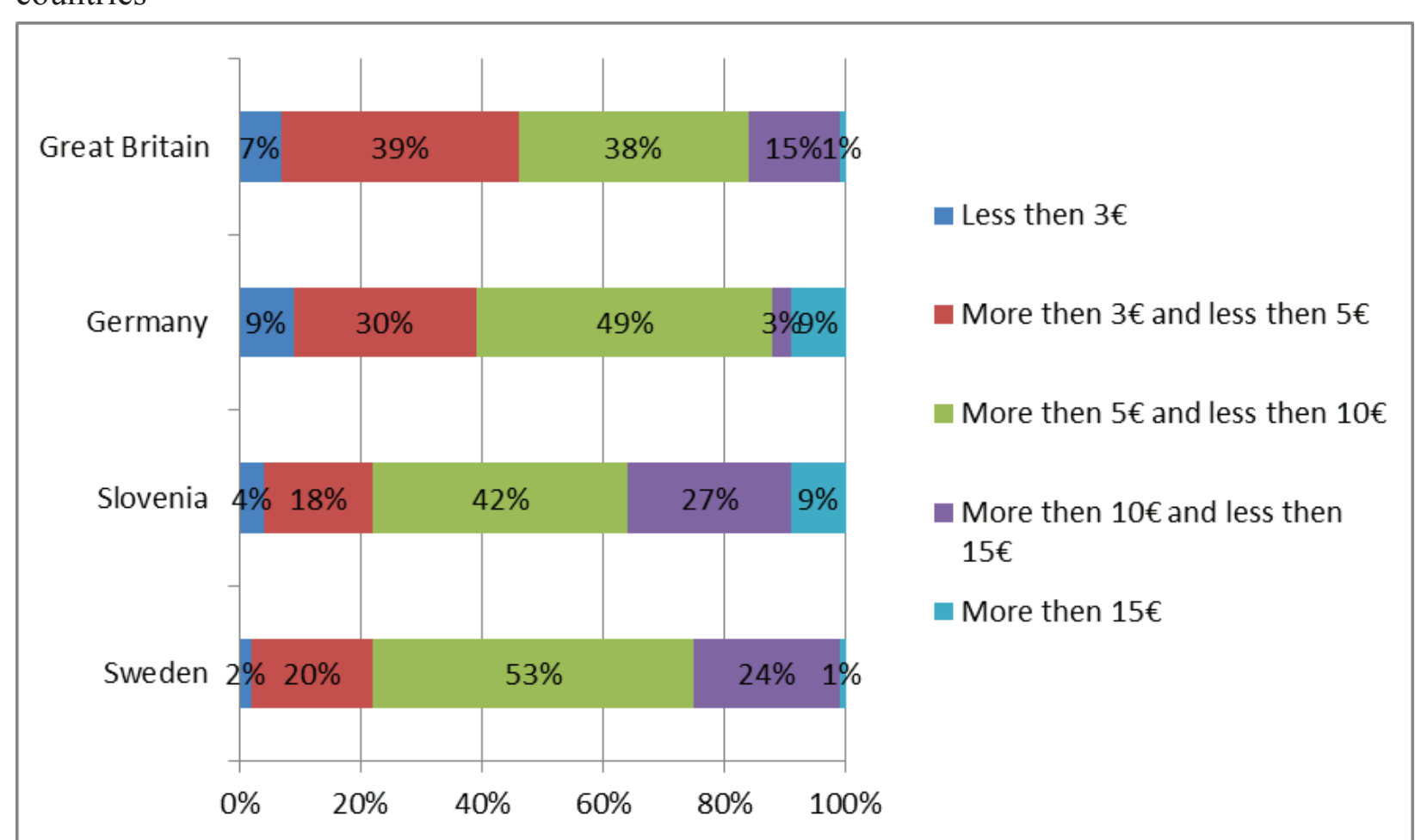

Source: Rihtaršič, own research 2014. 
Table 6: Monthly expenditure for feminine hygiene products in EUR in the selected countries

\begin{tabular}{|l|r|r|r|}
\hline & \multicolumn{1}{|c|}{ Number } & Arithmetic mean & \multicolumn{1}{c|}{$\begin{array}{c}\text { Standard } \\
\text { deviation }\end{array}$} \\
\hline Great Britain & 232 & 2,62 & 0,86 \\
\hline Germany & 209 & 2,71 & 0,99 \\
\hline Slovenia & 396 & 3,17 & 0,99 \\
\hline Sweden & 240 & 3,02 & 0,74 \\
\hline
\end{tabular}

Source: Rihtaršič, own research 2014.

Figure 3: Structural model of consumer behaviour

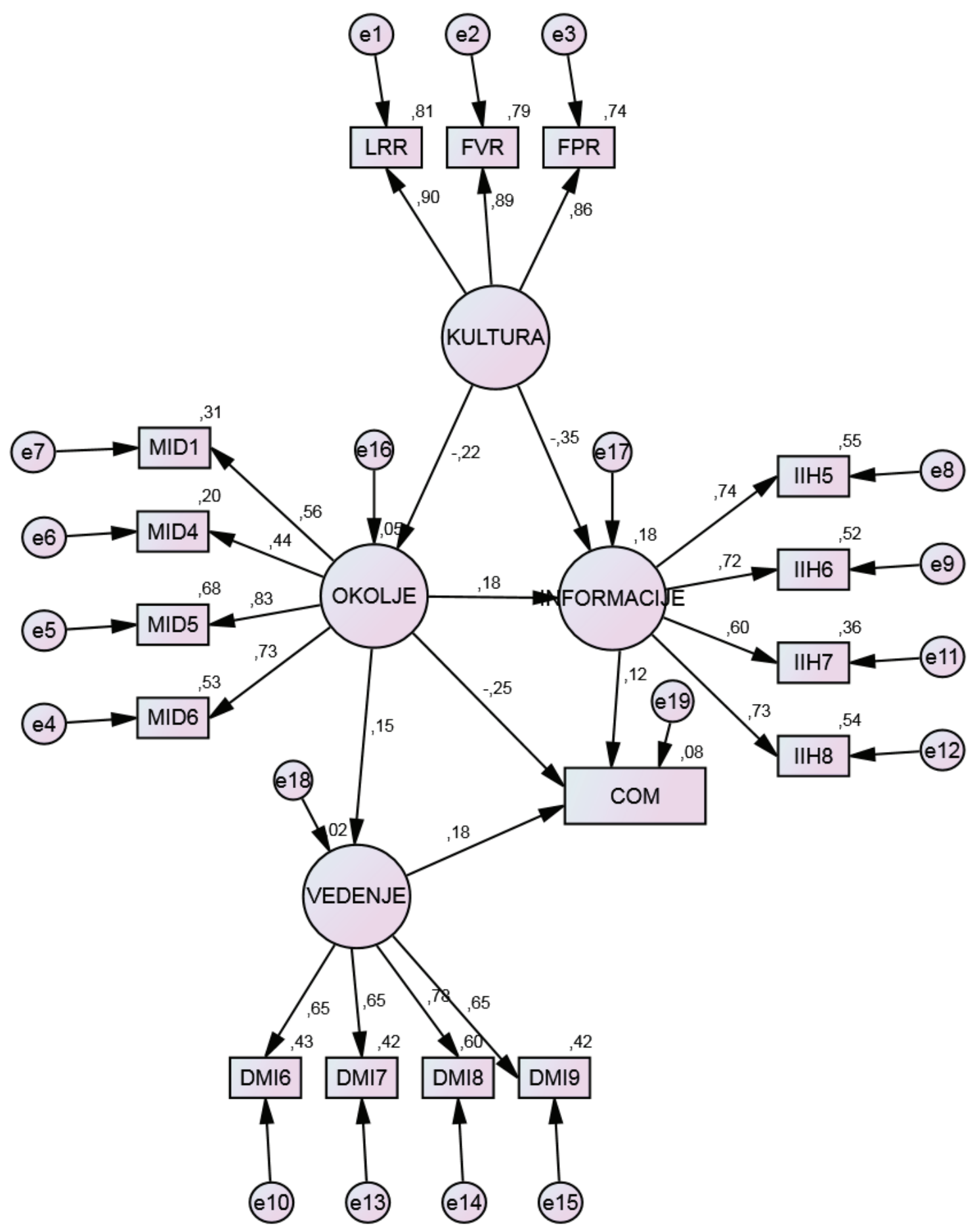

Source: Rihtaršič, own research 2014

Legend: "Kultura" - culture, "Informacije", information's, "Okolje" - environment, "Vedenje" behaviour, "Com" - expenses. 


\section{DISCUSSION}

Weights are presented in the above figure of the model. Culture negatively affects the environment as well as information. This is expected, since lower valued answers mean more open and modern society, whilst higher valued answers mean more closed and conservative society. Influence is negative. Influence is weak or medium and amounts to -0.22 or -0.35 . Environment affects information. The environment directly and indirectly affects behaviour. Influence on information is weak and amounts to 0.18. This can be explained by the fact that certain information remain taboos and that the effect of the environment is minimal. There is still insufficient discussion about menstruation and feminine hygiene products. Nobody wants to get exposed because of these topics. Influence of information on consumer behaviour is minimal. Direct effect of the environment on consumer behaviour is negative which means that those, who are more open in relation to menstruation, spend less.

\section{CONCLUSIONS AND IMPLICATIONS}

In this section we would like to especially underline and emphasize the sociologically interesting conclusion of our study that the globalization, daily migration of population and access to information in the observed EU countries from the field of female behaviour during menstruation, blurred the boundary between the urban and rural population. Nevertheless, it was shown that our above tested Model of consumer behaviour indicates great culturally conditioned differences between individual countries. The common model confirmed our assumptions (established on the basis of the insight into the theoretical background of the observed phenomenon) that the culture has negative affect both on the environment and information. Environment affects information. The environment directly and indirectly affects consumer behaviour. Effect on information is still weak because certain information remain taboo and because the environment only affects them in a very limited manner. Influence of the environment on behaviour is also weak. Direct effect of the environment on consumer behaviour is negative. There is still insufficient discussion on menstruation and feminine hygiene products in public and scarce research and discussion in academic spheres. In short, what all four countries from our study have in common is that the culture negatively affects the environment and information. On the other hand, good information is crucial for the development of ethical consumerism and changing of the consumer behaviour. Values, norms, rituals, signs and symbols keep changing, just like Mole says that »the culture is a living and changing system « (Mole, 2003). Under the influence of dynamic changes, cultures change as well. Openness of culture towards menstruation is, on one hand, historically connected with taboos and religion and, on the other hand, also with the dimensions of the culture.

Finally, we can see our above established model of female consumer behaviour as something practically useful and something that could be used in the economy and marketing. The results of the performed research indicate a process of the spiral transfer of cultural limitations and prejudices to the respondents through the environment.

Upon completion of the empirical research we recognized numerous possibilities to continue researching menstruation and ethical consumerism. Based on secondary data we can conclude that ethical consumerism appeared in the field of niche products, but slowly started to gain weight also in the field of feminine hygiene products. Nevertheless, information on suitable products and manufacturers in Europe is still scarce or non-existing. 
Besides, there are still not enough suitable natural products accessible in the market. Ethical consumerism is a process based on "positions, information and knowledge of products « (De Pelsmacker et al. 2005; Jelovac and Rihtaršič 2013). It would be useful to conduct a research on the existing ethical female consumers. Is ethical consumerism in the field of feminine hygiene a transfer of the consumer behaviour model from another category of products, or has it developed independently?
The results of the performed research indicate a process of spiral transfer of cultural limitations and prejudices to the respondents through the environment. Ethical consumerism in the field of feminine hygiene is currently in the development stage. Based on theoretical discourse and the results of the performed empirical research and observation of trends we expect an increase of ethical consumerism in the field of feminine hygiene in the future. 


\section{Literature}

1. BRIKMANN, JOHANNES. (2004) Looking at consumer behavior in a moral perspective. Journal of Busineess Ethics. 51 (2), page 129-141.

2. BRITTON, J. CATHRYN (1996) Learning about »the curse" An Antropological Perspective

3. BROWNE, ANGELA W. and PHIL J. C. HARRIS, ANNA H. HOFNY-COLLINS, NICK M. PASIECZNIK, AND R. R. WALLACE. (2000). Organic Production and Ethical Trade: Definition. Practice and Links. Food Policy. 25 (1), page 69-89.

4. BYRNE, M. BARBARA. 2010. Structural equation Modeling with AMOS: Basic concepts, Applications, and Programming. Routlage: New York.

5. CARRIGAN, MARYLYN, ISABELLE SZMIGIN and JOANNE WRIGHT. 2004.

Shooping for a better world? An interprative study of the potential for ethical consumption within the older market. Journal of Consumer Marketing 21 (6) 401-417

6. DAVIDSON, ANA (2012) Naratives of Menstrual Product Consumption: Convinience, Culture, or Commodization? Bulletin of Science, Technology \& Society, 32 (1), page 56-70.

7. DE PELSMACKER, PATRICK and WIM JASSENS (2007) Vpliv PT na nakupno vedenje potrošnikov trgovske verige Oxfam. Teorija in praksa, 5 (44), 709-732.

8. DESTATIS STATISTISCHE BUNDESAMT. Dostopno prek: http://www.destatis.de (25.1.2015).

9. DURKHEIM EMILE (1982) Elementarni oblici religijskog života. Beograd: Prosveta.

10. HAVENS, B., \& SWENSON, I. (1989). A content analysis of educational media about menstruation. Adolescence, 24, 901-907.

11. HAIR, F. JOSEPH JR. 2010. Multivariate data analysis. Upper Saddle River (NY): Prentice Hall.

12. HEINZE, THOMAS (1995)Qualitative Qualitative Sozialforschung: Einfubrung; Methodologie und Forschungpraxis. Wien: Oldenbourg.
12. HOFSTEDE, GEERT (2001) Culture's Consequences: Comparing Values, Behaviors, Institutions and Organizations Across Nations. (2nd ed.) London: Sage.

13. HOUPPERT, KAREN (1999) The curse: confronting the last unmentionable taboo: menstruation. New York; Ferar, Straus and Giroux.

14. HUNT, SHELBY D. and SCOTT VITELL. (1986) A General Theory of Marketing Ethics. Journal of Macro Marketing. 8 (Spring), page 5-16.

15. JELOVAC, DEJAN and RIHTARŠIČ, TANJA (2013) A Model of Slovenian Ethical Comsumerism. R\&R Raziskave in razpravel R\&DResearch and Discussion 2013, 6 (3), str. 115-146.

16. KALMAN, MELANIE BETH (2003) Adolscent girls single - parent fathers and menarche.

17. KISSLING, ELISABETH, ARVEDA (1996) That is just a basic teen age rules: Girls linguistic strategies for managing menstrual comunication taboo. Journal of Appliance Comunication Research. 24 (2), page 293-309.

18. KISSLING, ELISABETH, ARVEDA, (2006) Capitalizing on the course: the bussiness of menstruation. London: Lynne Reinner publishers inc.

19. KOFF, ELISSA and RIORDAN, JILL, JACOBSON, STACY (2011) The personal and interpersonal significanse of menarche. Journal of American Academy of Child Psychiatry. 20 (1), page 148-158.

20. PENDERGAST, SHIRLEY (1994) This is the Time to Grow up: girls. Experiences of menstruation in School. London: Family Planning Assosication.

21. REMBECK I., GUN and MOLLER, MARGARETA, GUNNARRSON K,. RONNY (2006)

Atitutdes and feelings towards menstruation and womanhood in girls at menarche. Acta pediatrica, 95 (1), page 707-714.

22. ROBERTS, JAMES A. (1996) Will the Real Socially Responsible Consumer Please Step Forward. Business Horizonts, 39 (4), 
page 97-117.

23. SHAW, DEIRDRE and IAN CLARKE. (1999) Belief Formation in Ethical Consumer Groups: An Exploratory Study. Marketing Intelligence \& Planing, 17 (2), page 109-119. 24. SHAW, DEIRDRE and EDVARD SHIU. (2002) The Role of Ethical Obligation And Self Identity in Ethical Consumer Choice. International Journal of Consumer Studies, 26 (2), page 109-116.

25. SHAW, DEIRDRE and EDVARD SHIU. (2003) Ethics in Consumer Choice: A Multivariate Modelling Approach. European Journal of Marketing, 37 (10), page 1485-1498.

26. STEIN, ELISA and SUSAN, KIM (2009) Flow: the cultural story of menstruation. New York: St. Martin's Griffin.

27. STATISTIČNI URAD REPUBLIKE SLOVENIJE. Dostopno prek: http://www. stat.si (25.1.2015)

28. UKÄ UNIVERSITET KENSLERS ÄM-
BETET. Dostopno prek: http://www.uk-ambetet.se (25.1.2015)

29. VITELL, SCOTT J., ANUSORN SINGHPAKDI IN JAMES THOMAS. (2001) Consumer Ethics: An aplication and Empirical Testing of the Hunt-Vitell Theory of Ethics. Journal of Consumer Marketing, 18(2), page 153-178.

30. WILKIE L. WILLIAM (1994) Consumer Behavior. Toronto: John Willey \& Sons, Inc. 31. WILLIAMS, L. R. (1983). "Beliefs and Attitudes of Young Girls Regarding Menstruation." In Menarche, ed. Sharon Golub. Lexington, MA: Lexington.

32. WINTHROP, ROBERT H. (1991) Dictionary of Concepts in Cultural Anthropology. New York: Greenwood Press.

33. ŽVELC, MAŠA (2003) Vloga družine in širšega socialnega okolja pri doživljanju menstruacije in menstrualnih bolečin. Časopis za kritiko znanosti, 212 (1), page 43-52. 